DOI https://doi.org/10.36059/978-966-397-156-8/42-63

\title{
BASIS OF ENVIRONMENTAL MONITORING OF POLLUTANTS
}

\section{Bondar O. I.}

\section{INTRODUCTION}

The ecological nature of chemical contamination manifests itself in destruction of the principles and rules of existence and functioning of biological systems in various levels, ranging from organism to biosphere. According to Teilhard de Chardin, the matter cannot be considered as the "matter-in-itself", that is to study the separated fragment from the whole outside the rest" ${ }^{1,2}$. After all, the part of ecosystem cannot develop independently. According to the one of the important ecological principle (namely "Principle of internal dynamic equilibrium"), the substance, energy, information and dynamic qualities of ecosystems and their hierarchies are interrelated so that any change in one of these indicators causes the functional and other changes in whole ecosystem ${ }^{3}$. This principle is one of the key provisions in environmental management.

While environmental changes are weak and arose on a relatively small area, they either are limited to a specific place, or "fading" in the chain of hierarchies of ecosystems. According to the second consequence of the above mentioned "Principle of internal dynamic equilibrium", as changes reach significant values for large ecosystems, they result in major displacements in broad natural units, up to the entire biosphere in the Earth. Being relatively irreversible, changes in nature finally become such that it is difficult to neutralize. After all, this changes correction requires considerable material costs and physical effort. Shifting the dynamic equilibrium of natural systems with considerable energy applications (eg. by plowing, the use of pesticides and other farming practices etc.) human disturbs normal

\footnotetext{
${ }^{1}$ Teilhard de Chardin P. The phenomenon of man, Mosc.: Science, 1987. 240 P.

${ }^{2}$ Reimers N. Nature Use: Dictionary. Mosc.: Thought, 1990. 637 P.

3 Reymers N.F. Ecology (theories, laws, rules, principles and hypotheses). Mosc.: Russia young, 1994, 367 P.
} 
functioning of environmental components, achieving an increase in useful bioproduction or comfortable conditions for life and human activities.

If the shears "fade" in the hierarchy of natural systems and do not cause a thermodynamic disorder in this natural system - ecosystem's conditions are satisfactory. However, excessive anthropogenic energy applying to ecosystem, which leads to a substance-energy disorder, leads to a decrease in natural resource potential, worsening of the hygienic conditions of human life, and the desolation of territories.

The future of mankind is determined by many circumstances. But among them there are two decisive ones. First: people must know the principles of the biosphere development, the possible causes of its degradation, be informed that they are allowed and where and the fatal limit that a human should not transgress under any circumstances. In other words, science, which is called ecology, must be able to formulate a Strategy in the relationships between nature and man. The second, equally important circumstance, without which it is unreasonable to talk about the future of mankind, is the need to approve such a social order that would be able to implement a system of limitations.

For 2 million years, humanity was in the homeostasis with the biosphere. Homeostasis was supported by the animist outlook ${ }^{4}$. This strategy of life ended when humankind learned to exploit natural resources. The result of this human occupation strategy for Nature is the boundary of the total ecological catastrophe after which biosphere can be transforms into a technosphere in one jump.

Today, the loss of productive land compared with the average annual rate of 10 thousand years of civilization has increased by 30 times. Dehumidification of soils has increased by 24 times, while the average yield increase over the past 50 years was only $30 \%$. There is the risk of disappearance for more than 26,000 species of plants and animals in the World, and for near 1000 species in Ukraine ${ }^{5}$. The

${ }^{4}$ Sytnyk K. Noosfera: myths and reality // Bulletin of the National Academy of Sciences of Ukraine, 2003, Vol. 2, pp. 51-62.

${ }^{5}$ Shelyagh-Sosonko Y.R. Biodiversity: the concept, culture and role of science // Ukrainian Botanical Journal, 2008, Vol. 65 (1), pp. 3-25. 
increasing of general biosphere ecological crises caused, of course, by an anthropogenic factor ${ }^{6}$.

The main role in the balanced development in biosphere plays, as is known, the regularity of the individuals' number in the trophic chain. This is a self-regulating system of "producers-consumentsreductants", and the number of individuals varies annually within a certain average. Thus, a balanced circulation of matter and, consequently, a component and territorial ecological balance are provided.

Plants are the source of the formation of phytomass and play a leading role in the presence of the complete conditions for healthy human functioning. Plants are not only oxygen source in biosphere, but also are producent in the trophic chains (in which human is a final link). Moreover, plants play an important role in the soil-forming process and in the soil buffer capacity. Additionally, plants are filtered biosphere as a buffer, which accumulates most of pollutants.

Plants play a main role in ensuring a balanced circulation of matter and, creating the thin membrane of life. The general trend and function of this membrane of life is biodiversity development, balancing of substances and energy in the environment in accordance with its energyaccumulating, geochemical, stabilizing and informational planetary roles. Plants, accumulating the energy of the Sun and producing biomass, ensures the functioning of the biosphere and its permanent composition as well as the territorial and component dynamic equilibrium in ecosystem. From the main function of ecosystems (the ability to accumulate energy in organic matter, in other words, productivity), from its size and dynamics completely depends the life of all existing on Earth.

In the context of any type of contamination by pollutants, the study of their migration is particularly important, since bioaccumulation of toxicants causes quantitative (decrease in productivity) and qualitative changes (increase in the content of pollutants in the plant and reduction of the required substances for the plant itself and consumpts). In this connection, the phytotoxicological scientific direction, which studies toxic effects on plants caused by any

\footnotetext{
${ }^{6}$ Zubakov V. Aspects of the ecogeosophical paradigm // Bulletin of the National Academy of Sciences of Ukraine, 2003, Vol. 1, pp. 30-38.
} 
origin pollutants, in particular, for the population level, is extremely relevant. To the indicator processes of the global ecological crisis, scientists include geochemical pollution of air, water and soil, geochemical poisoning of biota as a result of metallization, chemotoxication, radiootoxication, as well as activation of processes of technogenesis and violation of biogeochemical cycles in the biosphere.

\section{Pollutants in environment}

Areas of biological stability for ecological systems in general and individual organisms, under the influence of an anthropic factor, are characterized by narrow limits of changes. Chemical components through the atmosphere, soil or water enter the trophic chains, which leads to significant changes in the functioning of ecosystems and, in the end, negatively affect the livelihoods of the human. Excessive thresholds of reliability of ecological systems under the influence of extreme factors of anthropic origin may be the cause of environmental disasters.

In this regard, the study of harmful factors acting on man and biota becomes important. Of the existing dangerous agents, the most negative effects on living organisms are pollutants. As a result of many human activities, the contamination of the biosphere and the receipt of toxic chemicals of pollutants (pollutants) into the trophic chains occur in quantities that go beyond the normal content of natural limited fluctuations or the average natural background in the considered period. Alien to a living organism or their community, xenobiotics found a separate group of very dangerous pollutants.

Today, special attention to environment assessment is also given to such pollutants as persistent organic pollutants (POPs) which, according to the Stockholm Convention, are substances that have toxic properties, exhibit resistance to decomposition, are characterized by bioaccumulation and are the object of trans boundary transport by air, water and migratory species, and also sediment at a great distance from the source of their release, accumulate in the ecosystems of land and aquatic ecosystems ${ }^{7}$ (Figure 1).

${ }^{7}$ Stockholm Convention on Persistent Organic Pollutants (ukr / rus), the Law of Ukraine on Ratification of the Stockholm Convention on Persistent Organic Pollutants, URL: https://zakon.rada.gov.ua/laws/show/995_a07 
Typically, POPs are of anthropogenic origin, and their list of Annexes A and B of the Stockholm Convention includes pesticides: Aldrin, Chlorodan, Diederine, Endrin, Heptachlor, Mirex, Toxaphene, Dichlorodiphenyl trichloromethylmethane (DDT), which are now or are not used, or are restricted to application in agriculture, but often make up the hazardous waste . $^{8}$

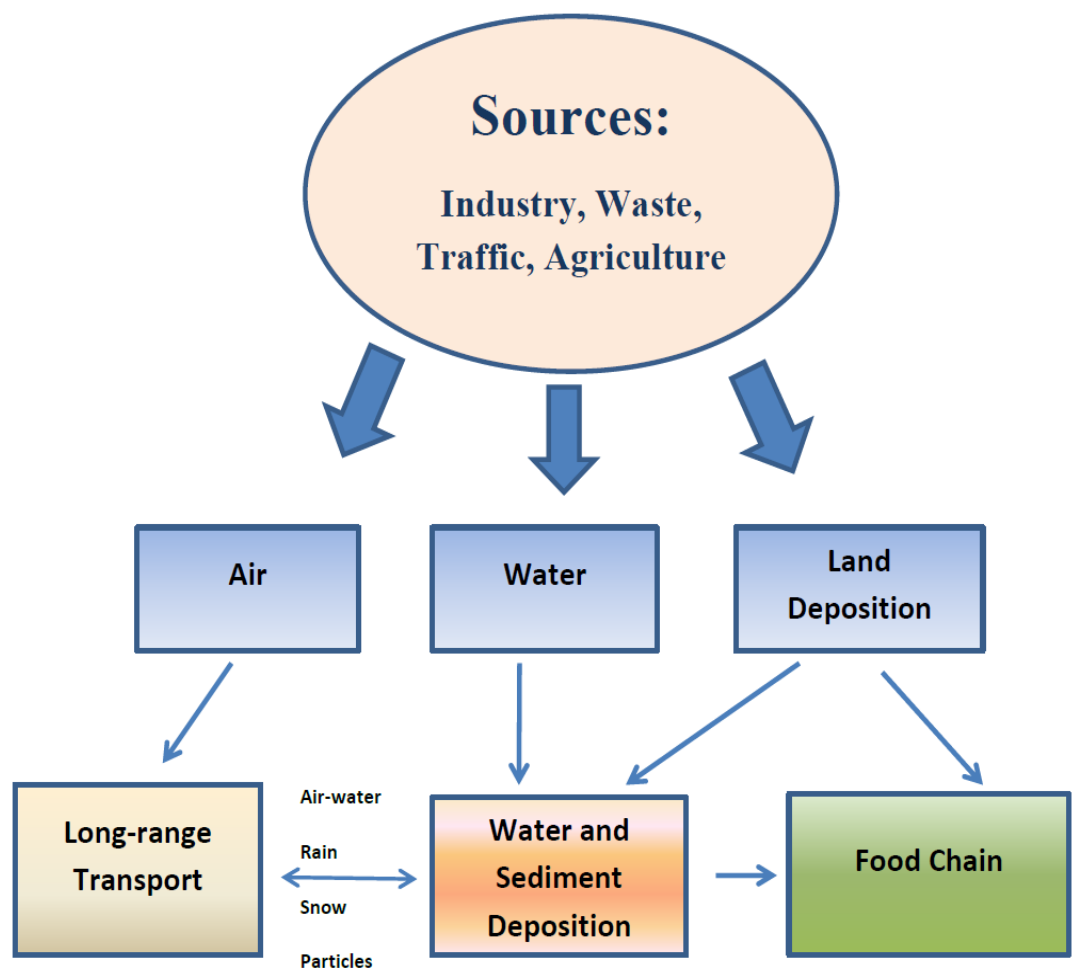

Fig. 1. POPs in the environment ${ }^{9}$

${ }^{8}$ Stockholm Convention on Persistent Organic Pollutants (ukr / rus), the Law of Ukraine on Ratification of the Stockholm Convention on Persistent Organic Pollutants, URL: https://zakon.rada.gov.ua/laws/show/995_a07

${ }^{9}$ Persistent organic pollutants (POPs). Children's Health and the Environment. WHO Training Package for the Health Sector. World Health Organization. www.who.int/ceh, July 2008 version 
POPs are released into air, water and land - from where they deposit into water, sediment, and enter the food-chain, are globally distributed through the air and ocean currents - they travel long distances and enter into atmospheric processes, air-water exchange and cycles involving rain, snow and dry particles. These processes lead to the exposure of even remote populations of humans and animals that depend on aquatic foods. Humans and animals are exposed mainly via ingestion of contaminated aquatic foodstuffs. POPs travel long distances and are found in places far away from industrial sites or from agricultural areas, such as the Arctic Circle ${ }^{10}$. Some POPs will almost always be found if tested for in tissues or environmental samples from different parts of the world. As is the case with many environmental pollutants, it is most difficult to establish that illness or diseases are directly attributable to exposure to a specific persistent organic pollutant or to a group of POPs. This difficulty is further underscored by (a) the fact that POPs rarely occur as a single compound, and (b) that individual field studies are insufficient to provide compelling evidence of cause and effect in their own right.

Polychlorinated dibenzo-para-dioxins (dioxins) and polychlorinated dibenzofurans (furans) are two groups of planar tricyclic compounds that have very similar chemical structures and properties. Their properties vary with the number of chlorine atoms present. Neither dioxins nor furans are produced commercially, and they have no known use. They are byproducts resulting from the production of other chemicals. Dioxins may be released into the environment through the production of pesticides and other chlorinated substances. Furans are a major contaminant of PCBs. Both dioxins and furans are related to a variety of incineration reactions, and the synthesis and use of a variety of chemical products. Dioxins and furans have been detected in emissions from the incineration of hospital waste, municipal waste, hazardous waste, cars, and the incineration of coal, peat and wood. Of the 210 dioxins and furans, 17 contribute most significantly to the toxicity of mixtures. At present, the only persistent effect associated with dioxin exposure in humans is chloracne.

${ }^{10}$ Persistent organic pollutants (POPs). Children's Health and the Environment. WHO Training Package for the Health Sector. World Health Organization. www.who.int/ceh, July 2008 version 
One of the most dangerous for environment and human health POPs are Polychlorinated biphenyls $(\mathrm{PCBs})^{11}$. PCBs are very stable chemicals, with low volatility at normal temperature (non-volatile below $40^{\circ} \mathrm{C}$ ), relatively fire-resistant and do not conduct electricity. PCB mixtures (of about 209 different compounds) are usually light coloured liquids that look like molasses. PCBs are soluble in most organic solvents but are almost insoluble in water. They were used in a wide range of industrial and consumer products, especially in the oil of electric capacitors (closed systems) and converters; as well as in coalmining. Overheating of electrical equipment containing PCBs can produce emissions of irritating vapours. $\mathrm{PCBs}$ are completely destroyed only under extremely high temperatures (over $1100^{\circ} \mathrm{C}$ ) or in the presence of certain combinations of chemical agents and heat. They are environmentally hazardous due to their extreme resistance to chemical and biological breakdown by natural processes in the environment. In the late 1960s the discovery of PCBs in birds in Sweden (by scientists researching DDT) and the outbreak of poisoning affecting 1200 people who had consumed rice oil contaminated with PCBs in Japan both focused public attention on the problem. PCBs have been released into the environment over the years, without any precautions, through open burning or incomplete incineration; by vaporization (from paints, coatings and plastics); by leakage into sewers and streams; by dumping in landfill sites, and by ocean dumping. Despite strict norms and regulations, PCBs may have been illegally dumped through ignorance, negligence or willfully ${ }^{12}$. The full health effects of PCBs on humans are unknown. It is unlikely that serious injury would result from short-term low-level exposure to PCBs. However, many are concerned about possible adverse health effects of long-term exposure to even low concentrations of these substances. Some PCB mixtures are suspected human carcinogens.

${ }^{11}$ Polychlorinated biphenyls (pcb) toxicity. U.S. Department of Health and Human Services Agency for Toxic Substances and Disease Registry Division of Toxicology and Environmental Medicine URL: https://www.atsdr.cdc.gov/HEC/CSEM/pcb/docs/pcb.pdf

${ }^{12}$ PERSISTENT ORGANIC POLLUTANTS (POPs). Children's Health and the Environment. WHO Training Package for the Health Sector. World Health Organization. www.who.int/ceh, July 2008 version 
By the opinion of many scientists, the typical composition of the geochemical man-made anomalies today is $\mathrm{Pb}, \mathrm{Cu}, \mathrm{Zn}, \mathrm{Mo}, \mathrm{Ba}, \mathrm{Co}$, $\mathrm{Mn}, \mathrm{Fe}, \mathrm{Ni}, \mathrm{As}$, as their accumulation in the environment continues at high rates. In the initial period of the formation of the industrial development of society, large man-made anomalies were formed by a significant number (more than 10) number of chemical elements. The elements with the highest contrast (with higher relative content) are called priority pollutants ${ }^{13}$. At the next stage of development of scientific and technological progress, the association of the composition of the geochemical anomaly will expand considerably.

According to of the ecological postulate (formulated by Alekseyenko), associations of chemical elements, forming large manmade geochemical anomalies, are determined mainly by the level of development of science and technology during the period of pollution $^{14,15}$. Gradually, the list of man-made sources of toxic metals in the ecosystem is expanding (Figure 2).

Environmental assessment of the pollutants danger includes one of the key indices - the intensity of migration in the ecosystem. It is known, that migration occurs in different vectors with different characteristics in environments. Today migration of substances is increasingly becoming anthropogenic rice. In this connection, the list of elements in the geochemical anomalies, which are formed as a result of the violation in the biogeochemical cycles, at a certain stage of society development, is comparatively constant ${ }^{16}$. According to the frequency, contamination can be systemic (with different frequency and duration), or impacted (one-time alarms with different quantitative effect). The main biogeochemical principles such as Main Biogeochemical Principle (formulated by Goldschmitt), and the Principle of Biogenic Migration of Atoms (formulated by Vernadsky) gave the possibility to distinguish a few essential paths of toxicants migration. There are physical migration and plant up-taking (Figure 3).

\footnotetext{
${ }^{13}$ Reimers N. Nature Use: Dictionary. Mosc.: Thought, 1990. 637 P.

${ }^{14}$ Reymers N.F. Ecology (theories, laws, rules, principles and hypotheses). Mosc.: Russia young, 1994, 367 P.

15 Dedyu I.I. Ecological Encyclopedic Dictionary. Chisinau: Heads. Ed. ITU, 1990, 408 P.

${ }^{16}$ Prokhorova N.V., Matveev N.M. Heavy metals in soils and plants in the conditions of technogenesis // Vestnik SamGU, 1996, Special issue, pp. 125-147.
} 


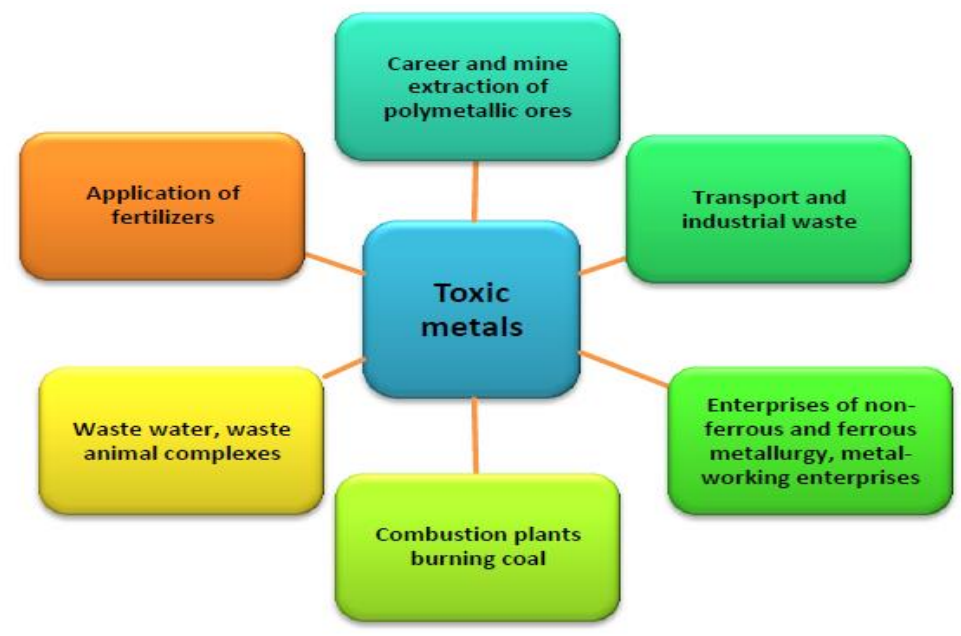

Fig. 2. The main sources of man-made toxic metals in ecosystems (by Honcharuk et al., 2017) ${ }^{17}$

Physical migration of pollutants depends on the structural and physical properties of the "soil-plant" system, which characterizes the ability of the ecosystems to be resistant (during possibly maximum period without pollutants adding into biogeochemical processes) ${ }^{18}$. The mechanism of activation of the bioaccumulative capacity of the ecosystem depends on the phytocomponent, because the phytocomponent, as a rule, plays a key role in the whole bioproductivity in the ecosystem and has environment generating function ${ }^{19}$. In this regard, the degree of biogeochemical active accumulation of contaminants determines the stability and balanced development of the ecosystem, and also characterizes the level of toxicity of toxicants to the ecosystem ${ }^{20}$.

17 Honcharuk E.A, Zagoskina N.V. Heavy metals: Entrance, toxicity and protective mechanisms of plants (by the example of cadmium ions) // Bulletin of Kharkiv National Agrarian University. Series Biology, 2017, Vol. 1 (40), pp. 35-49.

${ }^{18}$ Brian J. Alloway. Heavy metals in soils. Trace elements and Metalloids in Soils and their Bioavailability / Third ed. Alloway Brian J. UK, Springer, 2010. 235 p.

19 Ryzhenko N.O. Metals Phytotoxicity Assessment and Classification// International Letters of Natural Sciences. 2019, Vol. 73, pp. 17-25.

${ }^{20}$ Bondar OI, Ryzhenko N.O. Phytotoxicological classification of toxic metals according to the intensity of their bioaccumulation in the conditions of green parks zones of Kyiv // Agroecological journal, 2017, Vol. 3, pp. 32-40. 


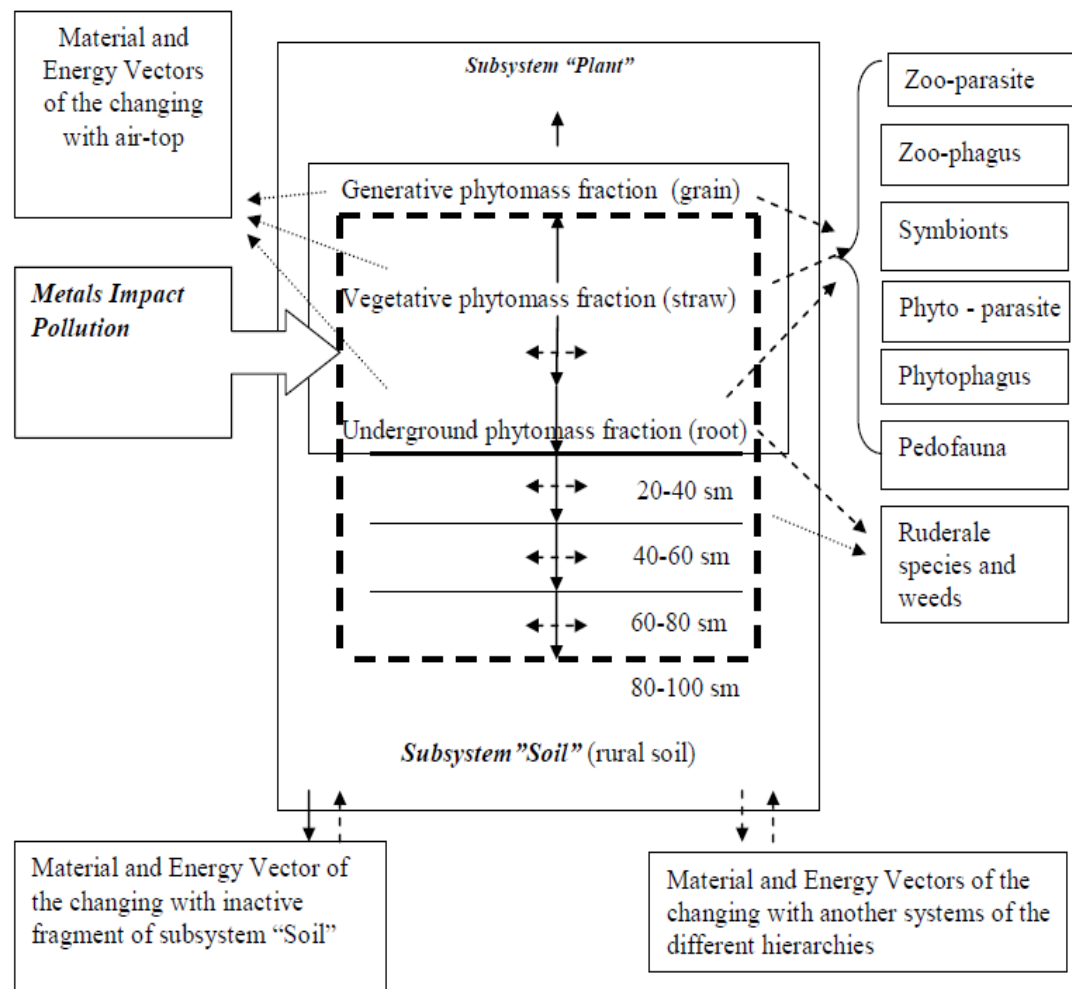

* the designation of the soil profile depth

$\longrightarrow$ The main migration ways

$-\rightarrow$ The minor migration ways (carrying-out $<0,01 \%$ of maintenance coming in from the impact pollution)

- The unessential migration ways (carrying-out $<0,001 \%$ of maintenance coming in from the impact pollution)

Remarks:

1. Scheme has been realized during conditional period of observation "from sowing to sowing"

2. The I, II, III consorts take place at HM carrying-out in the consortia level: animals - Phytophagus (trophic bond), parasite plant, animals, symbionts (tropic and topical bonds), saprotrophes,

3. Inactive fragment of subsystem "Soil" represented by soils layers lower $100 \mathrm{sm}$.

\section{Fig. 3. The Scheme of the ways of heavy metals (HM) migration in the "soil-plant" system"}

${ }^{21}$ Ryzhenko N., Kavetsky S., Kavetsky V. Heavy Metals (Cd, Pb, Zn, And Cu) Uptake By Spring Barley In Polluted Soils // Polish Journal Of Soil Science, Vol. Xlviii/1, 2015, pp. 111-129. 
One of the most dangerous inorganic pollutants is Mercury. Mercury is a highly toxic element that is found both naturally and as an introduced contaminant in the environment. Although its potential for toxicity in highly contaminated areas such as Minamata Bay, Japan, in the 1950's and 1960's, is well documented, research has shown that mercury can be a threat to the health of people and wildlife in many environments that are not obviously polluted. The risk is determined by the likelihood of exposure, the form of mercury present (some forms are more toxic than others), and the geochemical and ecological factors that influence how mercury moves and changes form in the environment.

The toxic effects of mercury depend on its chemical form and the route of exposure. Methyl mercury $\left[\mathrm{CH}_{3} \mathrm{Hg}\right]$ is the most toxic form. It affects the immune system, alters genetic and enzyme systems, and damages the nervous system, including coordination and the senses of touch, taste, and sight. Methyl mercury is particularly damaging to developing embryos, which are five to ten times more sensitive than adults. Exposure to methyl mercury is usually by ingestion, and it is absorbed more readily and excreted more slowly than other forms of mercury. Elemental mercury, $\mathrm{Hg}(0)$, the form released from broken thermometers, causes tremors, gingivitis, and excitability when vapors are inhaled over a long period of time. Although it is less toxic than methyl mercury, elemental mercury may be found in higher concentrations in environments such as gold mine sites, where it has been used to extract gold. If elemental mercury is ingested, it is absorbed relatively slowly and may pass through the digestive system without causing damage. Ingestion of other common forms of mercury, such as the salt $\mathrm{HgCl}_{2}$, which damages the gastrointestinal tract and causes kidney failure, is unlikely from environmental sources. People are exposed to methylmercury almost entirely by eating contaminated fish and wildlife that are at the top of aquatic foodchains. Alkali and metal processing, incineration of coal, and medical and other waste, and mining of gold and mercury contribute greatly to mercury concentrations in some areas, but atmospheric deposition is the dominant source of mercury over most of the landscape. Once in the atmosphere, mercury is widely disseminated and can circulate for 
years, accounting for its wide-spread distribution ${ }^{22}$. However, the prediction of the behavior in the environment of any toxicants requires a thorough study and the establishment of the limits and specifics of their migration. Toxicants' migration prediction will allow controlling the quality of the environment more efficiently.

The stability of ecosystems to the extreme effects of pollutants is determined not only by the intensity of the influence of the chemical factor (its dose and duration of action), but the ability of the toxicants to translocate and transform in the environment and living organisms. The study of these processes deals with ecotoxicology - a science that has recently been separated from the environment and has been widely developed. Migration of pollutants in the ecosystem is an obligatory indicator that allows assessing the toxicity of substances. The half-life of pollutants $\left(\mathrm{T}_{50}\right)$ as important index of pollutant toxicity characterizes the persistent as well as predicts contamination levels in the components of the ecosystem. The rate of reduction of toxicants contamination depends on the physical and chemical properties of the substances and the characteristics of the soil $(\mathrm{pH}$, granulometric composition, organic matter, plants canopy, etc.).

The main significant way of migration of pollutants in the ecosystem is bioaccumulation, which is influenced by a number of factors, such as physiological features of plants, type and level of contamination, geochemical capacity of the soil, etc. Bioaccumulation is an important index in the study of toxicity of pollutants, since this indicator not only allows for comparison of toxicity, but also predicts their hazard for biota. In this regard, the results of pollutants monitoring should include not only sanitary and hygiene indicators, but also ecotoxicological.

\section{Monitoring of pollutants in environment}

The value of developing an environmental monitoring system cannot be overestimated to assess the quality of human conditions. To determine and predict the risk of chemical pollution of the environment, a general methodological approach is used - continuous

${ }^{22}$ Environmental Mercury Mapping, Modeling, and Analysis (EMMMA). URL: https://www.usgs.gov/science-support/emmma 
monitoring of the conditions of pollution in the environment by chemicals and their impact on the health of the population, flora and fauna, and prediction of this impact in the future, which can be defined as environmental monitoring. The importance of and need for integrated environmental monitoring systems is well established.

Environmental monitoring is both: 1. Systematic observation of key environmental conditions; 2. Systematic verification of mitigation measure implementation. Systematic observation of key environmental conditions means that environmental indicators are chosen and assessed systematically. Indicators are signals of or proxies for environmental health and ecosystem function. Simple indicators can be more useful and appropriate than more complicated ones ${ }^{23}$.

Monitoring often requires systematic measurement of indicators to distinguish the impacts of the activity from other factors. A conceptual basis for the design of integrated monitoring systems and associated networks has received growing attention in the last two decades as part of scientific research to address environmental pollution from a local to global perspective ${ }^{24}$. The design of an integrated environmental monitoring strategy starts with identifying resources as risk in order to initiate development of a conceptual mode. This process of strategic planning is an iterative process whereby the model may be refined, elaborated, or enhanced based on practical and technical considerations, available resources, and defined monitoring objectives. This broad strategic approach usually will culminate in the development of testable questions that feed into the specifics of a detailed sampling and measurement design with a focus on parameter selection, quantifying data variability, and setting up a sampling scheme. This is also an iterative process with feedback to reframe questions and refine technical components of monitoring design. Data quality and statistical models for analyses also are identified as key

${ }^{23}$ Principles of Environmental Monitoring GEMS Environmental ComplianceESDM Training Series. URL: Senegal, February, 2014 http://www.usaidgems.org/ Workshops/SenegalRegional2014/Session\%206\%20-

\%20Env.\%20Monitoring/Senegal\%20MEO\%20Wkshp\%20Session6_Env\%20Monitor ing_11Feb2014pres.pdf

${ }^{24}$ D.A. Bruns and G.B. Wiersma Conceptual Basis of Environmental Monitoring Systems: A Geospatial Perspective, 2004, CRC Press LL, 334 P. 
components of this strategy. In monitoring toxic effects of point sources of pollutants, a conceptual model would identify critical sources of contamination inputs to the ecosystem and define which ecological receptors or endpoints (e.g., a particular species, a physical ecosystem compartment, or a target organ system) are likely to be impacted, modified, or changed. As a monitoring system is better defined, a more quantitative model or a suite of models based on different approaches (e.g., kinetic vs. numerical vs. statistical) may be used effectively to address complementary aspects of monitoring objectives. In monitoring pollutant impacts to streams and rivers, watershed boundaries may need to be established since upstream sources of contamination may be transported downstream during storm events, which may add uncertainty in the timing and movement of materials within the natural seasonal or annual patterns in the hydrologic cycle. For these reasons, a monitoring program should be flexible and maintain a continuous process of evaluating and refining the sampling scheme on an iterative basis. Conceptual components of environmental monitoring design and application includes application of a conceptual framework as a heuristic tool, evaluation of sourcereceptor relationships, multimedia sampling of air, water, soil, and biota as key component pathways through environmental systems, and use of key ecosystem indicators to detect anthropogenic impacts and influences. This conceptual approach allows identifying critical environmental compartments (e.g., air, water, soil) of primary concern, to delineate potential pollutant pathways, and to focus on key ecosystem receptors sensitive to general or specific contaminant or anthropogenic affects ${ }^{25}$.

Monitoring combines theoretical conclusions with practical recommendations and aims to justify the use of chemicals, the work of industrial objects, etc. environmental friendly. It should become part of a system of measures that ensure the internal dynamic balance of ecosystems.

The idea of implementing the ecological principles of the development of the national economy at the present stage of human

${ }^{25}$ D.A. Bruns and G.B. Wiersma Conceptual Basis of Environmental Monitoring Systems: A Geospatial Perspective, 2004, CRC Press LL, 334 P. 
existence should become dominant and non-alternative. The application of a systematic approach in monitoring is an important condition for effective solution of complex multi-task environmental problems. Due to the necessity to carry out an assessment of the quality of ecosystems, today the issue of environmental research is put on the agenda, which, first of all, contains a substantiated system of integral and indicative indicators. One of the directions of environmental monitoring is the identification of the real and potential hazards of chemicals, which is the main task of ecotoxicology.

The assessment of the level of hazard of substances makes it possible to predict the conditions of ecosystems. Under the threat of chemicals, the probability of occurrence of a human in contact with them is understood not only by acute and chronic poisoning, but also as a result of the general and selective action of chemicals of pathology, including the probable occurrence of specific long-term effects. This applies not only to the human body, but also to the negative effects of chemicals on ecosystem. In addition, the introduction of pollutants into the biogeochemical cycle leads to a shift in the energy balance of ecosystem and qualitative changes in its structure.

The normal functioning of the geochemical cycle is a guarantee of the internal dynamic equilibrium of ecosystems as the main condition for the existence of the biosphere. The Scheme of ecological monitoring system of pollutants in ecosystems is presented in Figure 4.

Environment monitoring systems can have two main types: permanent and periodically active. The periodically active system is used to solve specific problems during research or as an addition to permanent systems in the event of emergencies. Permanent operating systems are formed in the case of solving long-term tasks for monitoring harmful chemical pollutants of the environment and their effects on the human body, animals, plants, ecosystems, for prediction of this action, development of measures to eliminate their negative effects, etc.

The environmental monitoring is based on two main principles: unification and systematic. The first of them reveals mainly the functional side of the work of a particular system, the other structural. 


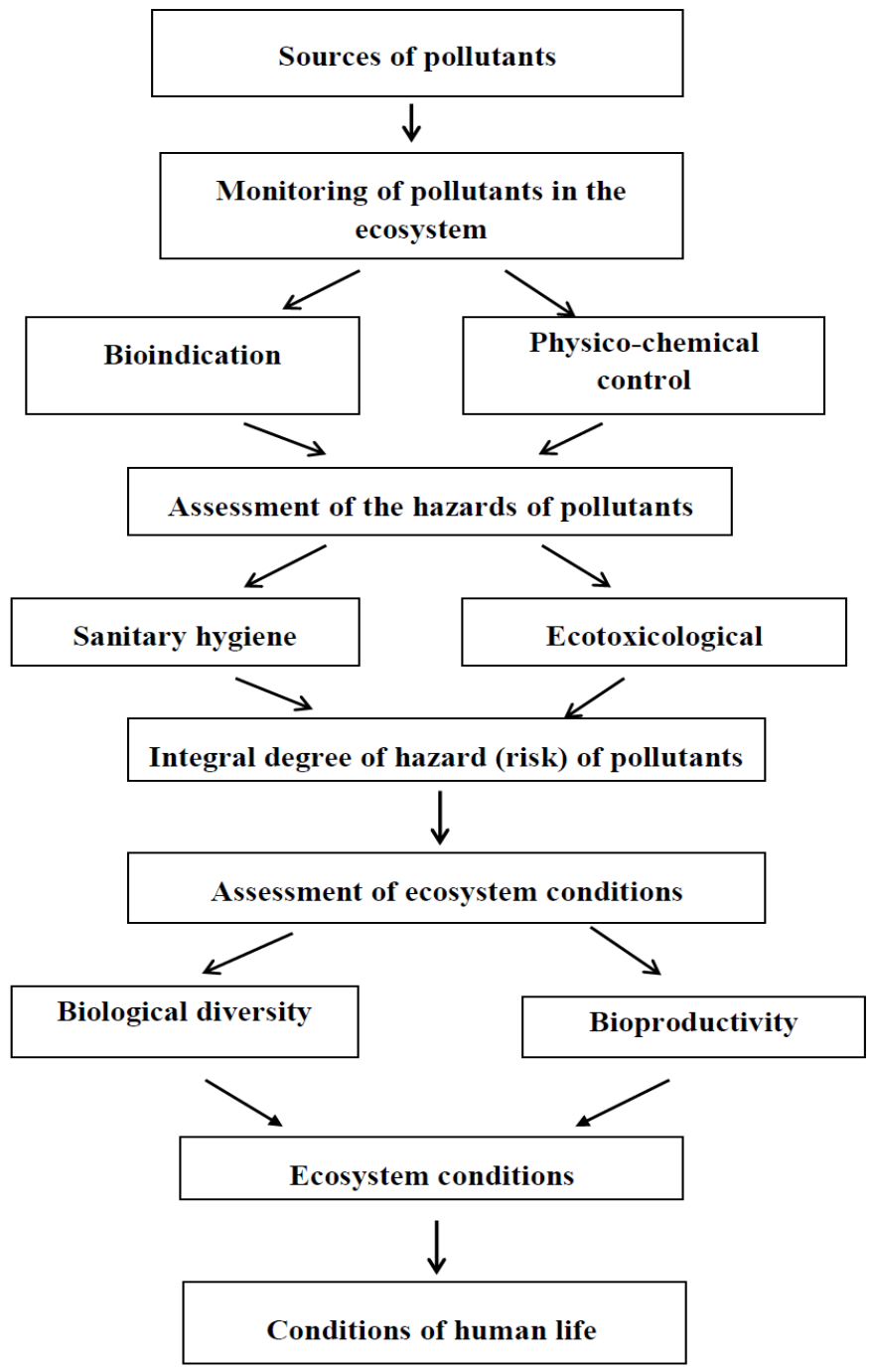

\section{Fig. 4. Scheme of ecological monitoring system of pollutants in ecosystems ${ }^{26}$}

${ }^{26}$ Bublik L.I., Kavetskyi V.M. Monitoring and ecotoxicological substantiation of application of chemical plant protection products // Plant protection and quarantine. 1996, Vol. 44. pp. 57-72. 
The principle of systems unification is realized through the uniform rules for sampling in researching, the equal methods for the detection of harmful chemicals in environmental objects and biota, the only criterion for obtaining the results, generalized software and information support and documentation forms. The principle of systematic is implemented by combining into the monitoring the main components of different levels such as district, city and others (depending on monitoring level).

The development and formation of environmental monitoring systems includes chemical and analytical, ecotoxicological, information, program and organizational support. The analytical support is one of the major elements in environment monitoring.

Analytical support provides the productivity and quality of monitoring implementation. Objectivity of analytical information regarding the content of toxic substances in environmental objects is ensured, first of all, by the presence of skilled specialists, qualitative sampling and adequate sample preparation of the material.

To ensure the accuracy of the determination of pollutants in the environment is possible only to choice the optimal standard methods (in accordance with the task of monitoring). The unification of methods of determination substance is very important also because it gives the possibility to obtain the correct data. Attestation of laboratories includes the presence of metrological characteristics of the methods in one laboratory, and a comprehensive evaluation of methods through interlaboratory testing with the participation of the most competent laboratories. Environmental Indicators may require laboratory analysis or specialized equipment and techniques ${ }^{27}$. The methods of laboratory analysis should be rapid (they determine the capacity of monitoring), and, if possible, simple. But at the same time methods must provide objective information about the content of certain toxic substances in the environment, and be accurate.

It is effective to assess the environment directly by of living organisms and their communities. It is obvious that the changes in

${ }^{27}$ Principles of Environmental Monitoring GEMS Environmental ComplianceESDM Training Series. URL: Senegal, February, 2014 http://www.usaidgems.org/ Workshops/SenegalRegional2014/Session\%206\%20-\%20Env.\%20Monitoring/Sene gal\%20MEO\%20Wkshp\%20Session6_Env\%20Monitoring_11Feb2014pres.pdf 
environment indicated by biota are very expressive for assessment and monitoring. "Living devices" in this sense are no worse than physical, and analysis of their "indicators" is no less important than the chemical analysis of soil, water, air. In some cases, this method of assessment is even better. Evaluating the environment by "living device" is important, because conditions of biota determine ecosystem conditions. However, the speed of reaction appearance in living organism in the result of pollution is not always suitable for environmental assessment. It is also an important task of monitoring to prevent pollution to manifestations of its effects in living organisms.

In addition, for the environment assessment, it is important to have a system of standards that could be linked to our understanding of the "ideal environment". Such samples are required for each naturalclimatic zone and should be provided by biosphere reserves as well as research stations with model crop rotation of cultivated plants.

To establish a comprehensive assessment of the pollutant's toxicity, it is advisable to use both sanitary-hygienic and ecotoxicological criteria. Ecotoxicological criteria are: stability of the pollutant in soil, water, biological objects, impact on the soil, phytotoxicity, toxicity on the entomophagus, fish, migration rate in the soil profile, plant up-taking, the formation of stable products of transformation, etc.

Integration of sanitary-hygienic and ecotoxicological criteria for assessing the toxicity pollutants enables the formation of information software, in which the accumulation and processing of information will allow to make appropriate decisions. The organizational support of the environment monitoring determines the general principles of their work, the structure, the list of documentation, the order and frequency of pollutants control in the environment.

The problem of environment monitoring of agroecosystem becomes also very important. New pesticides, growing of new species, applying of machinery in the fields, irrigation etc. in the agroecosystems are needs to monitoring and assessing.

Due to the fact that people directly use the field products, the evaluation of chemical agents is a priority task of environment monitoring. And in this case it is not enough to determine the quality indices of agricultural products. Only a comprehensive assessment of agroecosystem provides a complete the overview of the agroecosystem's state. The main potential pollutants of agroecosystem are pesticides and 
products of their metabolism, and also impurity substances in fertilizers. The volumes of chemical plant protection products are constantly increasing. The algorithm for assessing the risk of pesticide is based on the use of sanitary-hygienic and ecotoxicological criteria for obtaining the integral degree of pesticides hazard. The main sanitary-hygienic criterion is the dose of $\mathrm{LD}_{50}$, which causes the death of $50 \%$ of experimental animals $\left(\mathrm{mg} \cdot \mathrm{kg}^{-1}\right)$. Potential danger of pollution of the environment and food depends on the stability (persistence) of a pesticide, which is characterized by a period of its half-life $\left(T_{50}\right) . T_{50}$ is the time during which amount of pesticide is reduced by $50 \%$. The halflife of $\mathrm{T}_{50}$ is a key ecotoxicological criterion for hazardous substances. This indicator is a constant and independent of the initial concentration. Pesticides are considered practically safe if their dose $\mathrm{LD}_{50}$ exceeds $1000 \mathrm{mg} / \mathrm{kg}$, and $\mathrm{T}_{50}$ is less than 3 days ${ }^{28}$. The integral degree of danger (C) of each pesticide is estimated according to the equation: $\mathrm{C}=(\mathrm{Ka}+\mathrm{Kb})-1$, where $\mathrm{Ka}$ is toxicological and hygienic class of danger, $\mathrm{Kb}$ is ecotoxicological class of danger. The integral degree of danger (C) has 7 classes. Pesticides of 1 and 2 classes are very dangerous, 3 class are dangerous, 4 and 5 classes are moderately dangerous, 6 and 7 classes are not dangerous ${ }^{29}$. The dangers of pesticides is also determined by the maximum permissible concentrations (MAC) in soil, plant, water, air $\left(\mathrm{mg} \cdot \mathrm{kg}^{-1}, \mathrm{mg} \cdot \mathrm{l}^{-1}\right)$. Using pesticides and other agrochemicals humane effect primarily on the biosphere and living population. In accordance with Vernadsky's principles, this effect creates the preconditions for deeper chemical changes in the historical perspective. Consequently, the process can become self-evolving, not dependent on the desire of human and practically, in global volumes, unmanageable. The principle of biogenic migration of atoms determines the need for accounting, first of all, for the actions of biota and humans for local and regional changes in the negative chemical action, provides the keys for conscious and active prevention of and control of unwanted biochemical processes.

${ }^{28}$ Kavetsky V.M., Ryzhenko N.O. Physical and Chemical Criteria for Pesticides Determination and Risk Assessment in Ecosystem / V.M. Kavetsky, N.O. Ryzhenko // Polish J. Chem. Vol. 82, 2008, pp. 361-369.

${ }^{29}$ Bublik L.I., Kavetsky V.M. Monitoring and ecotoxicological substantiation of application of chemical plant protection products // Plant protection and quarantine. 1996, Vol. 44. P. 57-72. 


\section{CONCLUSIONS}

Pollutants (such as toxic metals, persistent organic pollutants etc.) through the atmosphere, soil or water enter the trophic chains, which leads to significant changes in the functioning of ecosystems and, in the end, negatively affect the livelihoods of the human. This affect creates the preconditions for deeper chemical changes in the historical perspective. Consequently, the process can become self-evolving, not dependent on the desire of human and practically, in global volumes, unmanageable. Therefore, monitoring of pollutants becomes important tool tracking changes in the environment.

Both activities on quality improvement of the polluted environment and-a willingness to understand these processes are conditional on possessing reliable information that can be obtained from environmental monitoring. The application of a systematic approach in environmental monitoring of pollutants is an important for effective solution of complex multi-task environmental problems. The principles and concepts of environmental monitoring design are dynamic and iterative in nature. The objective assessment of the pollutants in environment involves some stages: (1) quantitative evaluation of pollutants in the environment (soil, plants, water, air, etc.); (2) assessment of biota intoxication; (3) forecasting the consequences of pollution. Objective observations obtained as a result of environmental monitoring produce the valuable information. Information-derived knowledge usually leads to an enhanced understanding of the environment pollution and situation, which improves the chances of making informed decisions.

\section{SUMMARY}

The article is devoted to the basis of pollutants monitoring in environment. The design of an integrated environmental monitoring strategy starts with identifying resources as risk in order to initiate development of a conceptual model. It is presented, that the environmental monitoring is based on two main principles: unification and systematic. The objective assessment of the pollutants in environment involves: quantitative evaluation of pollutants in the environment (soil, plants, water, air, etc.); assessment of biota intoxication; forecasting the consequences of pollution. Information-derived knowledge usually leads to an enhanced understanding of the environment pollution and situation, which improves the chances of making informed decisions. 


\section{REFERENCES}

1. Bondar O.I., Ryzhenko N.O. Phytotoxicological classification of toxic metals according to the intensity of their bioaccumulation in the conditions of green parks zones of Kyiv // Agroecological journal, 2017, Vol. 3, pp. 32-40.

2. Brian J. Alloway. Heavy metals in soils. Trace elements and Metalloids in Soils and their Bioavailability / Third ed. Alloway Brian J. UK, Springer, 2010. 235 p.

3. Bruns D.A. and Wiersma G.B. Conceptual Basis of Environmental Monitoring Systems: A Geospatial Perspective, 2004, CRC Press LL, 334 p.

4. Bublik LI, Kavetskyi VM Monitoring and ecotoxicological substantiation of application of chemical plant protection products // Plant protection and quarantine. 1996, Vol. 44. P. 57-72.

5. Dedyu I.I. Ecological Encyclopedic Dictionary. Chisinau: Heads. Ed. ITU, 1990, 408 p.

6. Environmental Mercury Mapping, Modeling, and Analysis (EMMMA). URL: https://www.usgs.gov/science-support/emmma

7. Honcharuk E.A, Zagoskina N.V. Heavy metals: Entrance, toxicity and protective mechanisms of plants (by the example of cadmium ions) // Bulletin of Kharkiv National Agrarian University. Series Biology, 2017, Vol. 1 (40), pp. 35-49.

8. Kavetsky V.M., Ryzhenko N.O. Physical and Chemical Criteria for Pesticides Determination and Risk Assessment in Ecosystem / V.M. Kavetsky, N.O. Ryzhenko // Polish J. Chem. Vol. 82, 2008, pp. 361-369.

9. Persistent organic pollutants (POPs). Children's Health and the Environment. WHO Training Package for the Health Sector . World Health Organization. www.who.int/ceh, July 2008 version

10. Polychlorinated biphenyls (pcb) toxicity. U.S. Department of Health and Human Services Agency for Toxic Substances and Disease Registry Division of Toxicology and Environmental Medicine URL: https://www.atsdr.cdc.gov/HEC/CSEM/pcb/docs/pcb.pdf

11. Principles of Environmental Monitoring GEMS Environmental Compliance-ESDM Training Series. URL: Senegal, February, 2014 http://www.usaidgems.org/Workshops/Senegal Regional2014/Session\%206\%20-\%20Env.\%20Monitoring/Senegal 
\%20MEO\%20Wkshp\%20Session6_Env\%20Monitoring_11Feb2014 pres.pdf

12. Prokhorova N.V., Matveev N.M. Heavy metals in soils and plants in the conditions of technogenesis // Vestnik SamGU, 1996, Special issue, pp. 125-147.

13. Reimers N. Nature Use: Dictionary. Mosc.: Thought, 1990. $637 \mathrm{P}$.

14. Reymers N.F. Ecology (theories, laws, rules, principles and hypotheses). Mosc.: Russia young, 1994, 367 P.

15. Ryzhenko N., Kavetsky S., Kavetsky V. Heavy Metals $(\mathrm{Cd}, \mathrm{Pb}, \mathrm{Zn}$, And $\mathrm{Cu})$ Uptake By Spring Barley In Polluted Soils // Polish Journal Of Soil Science, Vol. Xlviii/1, 2015, pp. 111-129.

16. Ryzhenko N.O. Metals Phytotoxicity Assessment and Classification// International Letters of Natural Sciences. 2019, Vol. 73, pp. 17-25.

17. Shelyagh-Sosonko Y.R. Biodiversity: the concept, culture and role of science // Ukrainian Botanical Journal, 2008, Vol. 65 (1), pp. 3-25.

18. Stockholm Convention on Persistent Organic Pollutants (ukr / rus), the Law of Ukraine on Ratification of the Stockholm Convention on Persistent Organic Pollutants, URL: https://zakon.rada.gov.ua/ laws/show/995_a07

19. Sytnyk K. Noosfera: myths and reality // Bulletin of the National Academy of Sciences of Ukraine, 2003, Vol. 2, pp. 51-62.

20. Teilhard de Chardin P. The phenomenon of man, Mosc.: Science, 1987. 240 P.

21. Zubakov V. Aspects of the ecogeosophical paradigm // Bulletin of the National Academy of Sciences of Ukraine, 2003, Vol. 1, pp. 30-38.

\section{Information about the author: Bondar O. I.,}

Doctor of Biology, Professor, Corresponding Member of the Academy of Agrarian Sciences of Ukraine, Rector of State Ecological Academy of Post-Graduate Education and Management 35 build. 2, Vasylya Lypkivskogo str., Kyiv, 03035, Ukraine 